OPEN ACCESS

Edited by:

Mieke Van Hemelrijck, King's College London,

United Kingdom

Reviewed by:

Wahyu Wulaningsih, King's College London, United Kingdom

Elke Rammant,

Ghent University, Belgium

*Correspondence: Ying Zheng

zhengying@fudan.edu.cn

Specialty section

This article was submitted to Cancer Epidemiology and Prevention,

a section of the journal

Frontiers in Oncology

Received: 19 May 2020 Accepted: 02 September 2020

Published: 20 October 2020

Citation:

Zhou C, Mo M, Wang Z, Shen J, Chen J, Tang L, Qiu J, Ling Y, Ding H,

Jiang $Q$, Wang $H$, Shao $Z$ and

Zheng Y (2020) A Short-Term Effect

of Wearable Technology-Based

Lifestyle Intervention on Body

Composition in Stage 1-III

Postoperative Breast Cancer

Survivors. Front. Oncol. 10:563566.

doi: 10.3389/fonc. 2020.563566

\section{A Short-Term Effect of Wearable Technology-Based Lifestyle Intervention on Body Composition in Stage I-III Postoperative Breast Cancer Survivors}

\begin{abstract}
Changming Zhou ${ }^{1,2}$, Miao Mo ${ }^{1,2}$, Zezhou Wang ${ }^{1,2}$, Jie Shen 1,2, Jiajian Chen 2,3, Lichen Tang ${ }^{2,3}$, Jiajia Qiu'2,3, Yiqun Ling ${ }^{2,4}$, Huiping Ding ${ }^{2,4}$, Qin Jiang ${ }^{5}$, Hui Wang ${ }^{6}$, Zhimin Shao ${ }^{2,3}$ and Ying Zheng ${ }^{1,2 *}$
\end{abstract}

\begin{abstract}
1 Department of Cancer Prevention, Fudan University Shanghai Cancer Center, Shanghai, China, ${ }^{2}$ Department of Oncology, Shanghai Medical College, Fudan University, Shanghai, China, ${ }^{3}$ Department of Breast Surgery, Fudan University Shanghai Cancer Center, Shanghai, China, ${ }^{4}$ Department of Nutrition, Fudan University Shanghai Cancer Center, Shanghai, China, ${ }^{5}$ Shanghai Ruochu Information Technology Co., Ltd., Shanghai, China, ${ }^{6}$ Huami Information Technology Co., Ltd., Beijing, China
\end{abstract}

Background and Aim: A healthy body composition can improve the prognosis of breast cancer survivors. The study aimed to describe the body composition profile of breast cancer survivors and find out whether a short-term (3 months) wearable device-based lifestyle intervention had an effect on patients' body weight and body composition.

Methods: A before-and-after study was conducted on patients with stage I-III postoperative breast cancer, aged 18-70 years. Body composition was analyzed at baseline, and then patients went for a health education program. A wearable activity tracker and a goal of calorie consumption based on each individual's weight were provided to each participant, and they were required to be equipped for 90 days. After 3 months, body composition was analyzed again.

Results: Of 113 patients who completed the study, 65.49\% showed a normal body mass index (BMI) at baseline assessment, $71.68 \%$ had a body fat percentage of more than $30 \%$, and $41.59 \%$ had less skeleton muscle mass. During the intervention, the daily step count was $8,851.28 \pm 2,399.31$, and $59.21 \%$ reached the set goal calorie consumption. After a 3-month intervention, the patients had a significant reduction in body weight, fat mass, BMl, body fat percentage, and visceral fat area, but not in protein mass and skeleton muscle mass. Patients of different age, molecular classification, and therapy benefited from the intervention.

Conclusion: Wearable technology with body composition analysis and health education for breast cancer survivors may help reduce weight and improve body composition even in a short time.

Clinical Trial Registration: http://www.chictr.org.cn/showproj.aspx?proj=40672, identifier ChiCTR1900024258.

\footnotetext{
Keywords: breast cancer, body weight, body composition, life-style intervention, wearable technology
} 


\section{BACKGROUND}

Breast cancer is the most common cancer among women, with more than 2 million new cases worldwide each year (1). The survival of patients with breast cancer has greatly improved with enhanced screening programs and advance treatment strategies. The 5-year survival rate of breast cancer in China is $83.2 \%$ (2) and more than $90 \%$ in developed regions such as Shanghai (3). The prognosis of patients with breast cancer needs to be improved. It is hard to evaluate the effect of the intervention on survival through a short-term trial because the survival of breast cancer is relatively good, and events are hard to be observed during a short term.

A previous study showed that patients with breast cancer had an increase in body weight of $2.7 \mathrm{~kg}$ during chemotherapy (4). The reason for the body weight gain during chemotherapy could be complex, including overeating related to psychological factors, decreased physical activity, use of steroids, and loss of ovarian function associated with chemotherapy, which results in hormonally mediated changes in fat accumulation and distribution (5). Increasing evidence showed that weight was associated with the risk of breast cancer, especially ER+/PR+ invasive breast cancer, among postmenopausal women (6), and high body weight and high body fat were related to poorer outcomes, with an increased mortality risk of $17 \%$ per $5 \mathrm{~kg} / \mathrm{m}^{2}$ (7). The summary relative risk of total mortality was 1.41 and 1.07 for obese and overweight women, respectively, compared with normal-weight women (8). Evidence also showed that high body fat increased the risk of all-cause mortality and breast cancer mortality during both pre-diagnosis and postdiagnosis periods (9). The obese adipose tissue can release or regulate more than 50 different cytokines, chemokines, and hormone-like factors, including HIF-1, leptin, and adiponectin (9) (10), which promote angiogenesis by turning on vascular endothelial growth factor. The released free fatty acids can also activate the NF- $\mathrm{B}$ pathway, which increases aromatase expression and estrogen synthesis (11). Hence, body weight, body mass index (BMI), body fat, or physical activity status may serve as intermediary indicators predicting the survival of breast cancer survivors.

Good results were achieved in patients' weight control. Studies showed that physical activities reduced the recurrence, breast cancer-specific mortality, and all-cause mortality (1215). However, these studies mostly focused on obese patients, and the intervention was intensive monitoring through large workloads such as telephone supervision (16), which made it hard to be popularized.

Wearable technology, such as wearable activity trackers, has the potential to facilitate these activities through continuous monitoring and feedback (17), even with health promotion and peer support; each device is less expensive. This technology has been widely used in the management of diabetes, physical inactivity, and smoking (18). It also can potentially benefit cancer survivors who have a comparatively good prognosis, such as in breast cancer and in colorectal cancer. However, studies using such devices and technology are limited because this technology has bloomed only in recent years.
This study aimed to describe the body composition profile of general breast cancer survivors and find out whether a short-term (3 months) wearable device-based lifestyle intervention had an effect on patients' body composition, such as fat mass, body fat percentage, and skeleton muscles, and to explore the technology's acceptance among breast cancer survivors.

\section{MATERIALS AND METHODS}

\section{Study Design}

A before-and-after comparison was conducted among the eligible patients in Fudan University Shanghai Cancer Center. Data on demographics, dietary status, quality of life (QoL), and body composition were collected at baseline. Then, a wearable technology-based lifestyle intervention, which facilitated both data collection and physical activity supervision, was offered to the participants. After 3 months, the patients were required to fill in the QoL questionnaire and undergo a test on body composition again, with satisfaction and adverse effects recorded.

\section{Patients}

Patients with stage I-III postoperative breast cancer, aged 18-70 years, were included in the program. The inclusion criteria were as follows: (1) all patients needed to complete major treatment, including surgery, adjuvant chemotherapy, or adjuvant radiotherapy, for at least 1 year but could be under endocrine therapy and (2) all patients were required to be equipped with a smartphone for app installation. The exclusion criteria were as follows: (1) with distant metastasis, (2) pregnant or breastfeeding, (3) with a severe mental disorder or substance abuse, (4) with diseases or injuries, making them unable to take part in physical activities, including fracture, limb disability, and rheumatic arthritis, and (5) those who already joined other physical activityrelated programs. Patients who applied for the program were screened using an online questionnaire. The participants were scheduled to be selected from all the eligible patients using a simple random sampling method.

\section{Intervention}

A wearable activity tracker (Mi band 2, developed by Huami Corporation and based on the Amazfit health cloud data services) was given to the participants, and they were guided to use the equipment. Then, face-to-face health education, as well as a pamphlet on lifestyle guidelines for breast cancer survivors, was provided to each participant according to the guidelines on lifestyle modification for Chinese breast cancer survivors (19), emphasizing on at least $150 \mathrm{~min}$ of moderate-to-vigorous physical activities (MVPAs) per week. An equivalent of 30min moderate physical activity calorie consumption goal was set based on each participant's weight. The participants were suggested to complete the calorie consumption goal daily during the 3-month intervention. They could get access to the real-time calorie consumption data from the app (Mi Fit) synchronized with the equipment. 


\section{Data Collection}

The demographic information of patients was collected using a structured questionnaire. Data on dietary status were collected using a food frequency questionnaire. Both parts were conducted online and filled in under the guidance of a trained investigator. The QoL was assessed using the Functional Assessment of Cancer Therapy-Breast Cancer scale developed by Cella (20) and translated into simplified Chinese. It comprised 27 general items in four domains (physical well-being, social/family well-being, emotional well-being, and functional well-being) and nine items in breast cancer-specific domain (21). Disease- and treatmentrelated information was collected from a structured breast cancer database. Body weight, protein mass, fat mass, skeletal muscle mass (SMM), BMI, percentage body fat (PBF), basal metabolic rate (BMR), and visceral fat area (VFA) were measured as body composition indicators by the bioelectrical impedance analysis method (22) using an InBody S10 body composition analyzer. The activity data collection included step numbers, walking time, running time, daily calorie consumption (based on the activities monitored), daily running-specific calorie consumption, and

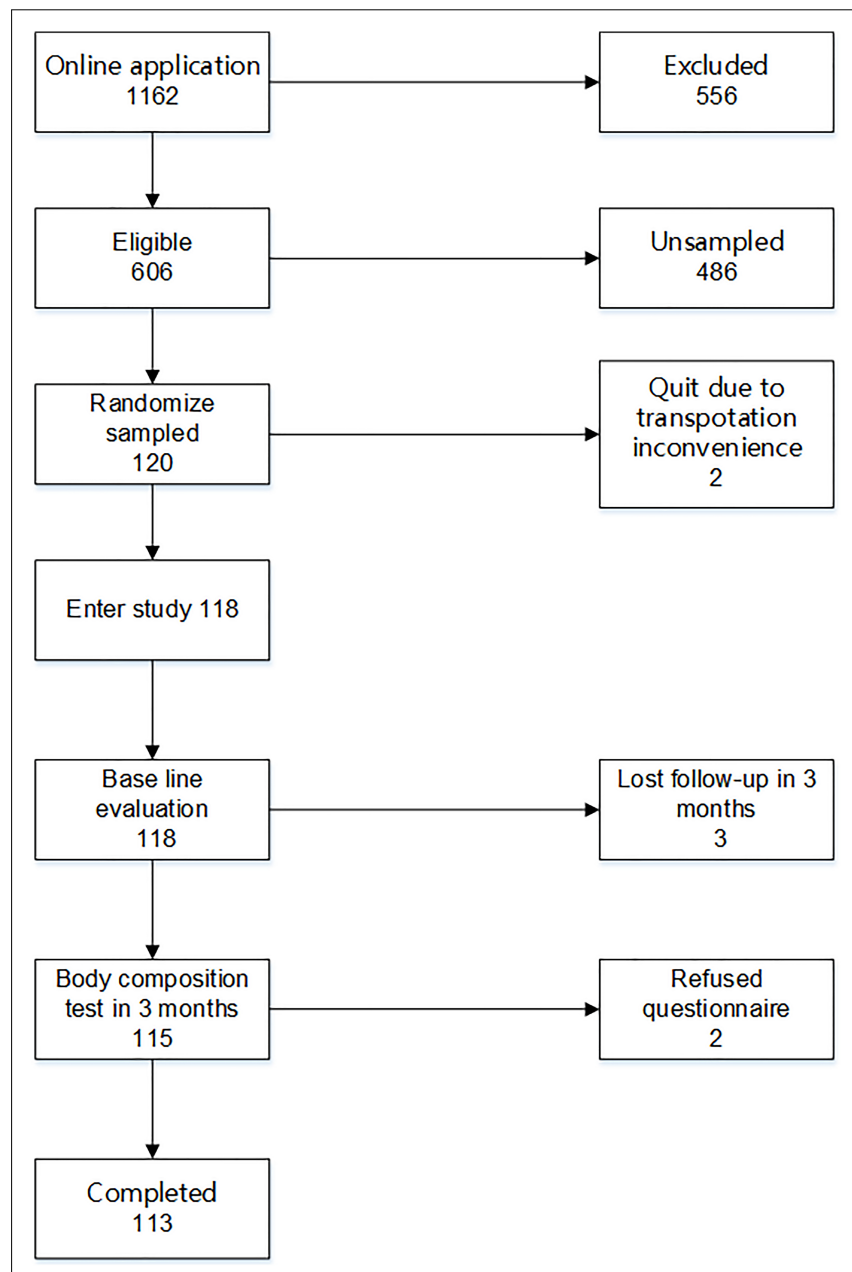

FIGURE 1 | Flow diagram of participants in the program. sleep status (awake, deep sleep, and light sleep). The data were stored in the band for up to 30 days and, once linked to the app (Mi Fit), they were synchronized to the user's account. With prior authorization from all the participating patients, the daily statistics data of each patient were transferred to a patients' health management system developed by Shanghai Ruochu Information Technology Co., Ltd.

\section{Statistical Analysis}

Number and percentages were used for describing categorical variables, while means \pm standard deviation and median (quartiles) were used for describing measurement data depending on whether the distribution was normal. Paired-sample $t$ test was used to analyze the before-and-after body composition at a statistically significant level $(\alpha=0.05)$. All analyses were performed using SPSS 21.0 (IBM Corp., United States).

\section{RESULTS}

From November 8, 2017 to March 22, 2018, 118 eligible patients were randomly recruited in the study and completed the baseline assessment. Then, each participant was invited to an online Wechat group community. After a 3-month intervention, 113 patients completed the final assessment; two refused to take the 3-month assessment due to inconvenience in transportation, and

TABLE 1 | Baseline characteristics of the participants.

\begin{tabular}{|c|c|c|c|}
\hline Characteristics & $n=113$ & Characteristics & $n=113$ \\
\hline Age $($ mean $\pm S D)$ year & $48.83 \pm 8.44$ & Lymph node & \\
\hline Time to surgery (year) & & Negative & 69 (61.06) \\
\hline $1 \sim$ & $49(43.36)$ & Positive & 44 (38.94) \\
\hline $2 \sim$ & $23(20.35)$ & Chemotherapy & \\
\hline $3+$ & $41(36.28)$ & Yes & $101(89.38)$ \\
\hline Education & & No & $12(10.62)$ \\
\hline Junior school & $12(10.62)$ & Endocrine therapy & \\
\hline High school & $34(30.09)$ & Yes & $82(72.57)$ \\
\hline College & $59(52.21)$ & No & $31(27.43)$ \\
\hline Postgraduate & $8(7.08)$ & Molecular classification & \\
\hline Marriage & & Luminal $\mathrm{A}$ and $\mathrm{B}$ & $82(72.57)$ \\
\hline Never married & $3(2.65)$ & HER-2 enriched & $11(9.73)$ \\
\hline Married & $104(92.04)$ & Triple negative & $18(15.93)$ \\
\hline Divorced/Separated & $5(4.42)$ & Not identified & $2(1.77)$ \\
\hline Widowed & $1(0.88)$ & $\mathrm{BMI}\left(\mathrm{kg} / \mathrm{m}^{2}\right)$ & \\
\hline Employment & & $<18.5$ & $6(5.31)$ \\
\hline Employed/Retired & 87 (76.99) & $18.5-23.9$ & $74(65.49)$ \\
\hline Unemployed & $8(7.08)$ & $24-27.9$ & $26(23.01)$ \\
\hline Others & $16(14.16)$ & $\geq 28$ & 7 (6.19) \\
\hline Household income per capita & & SMM & \\
\hline$<¥ 6000$ & $35(30.97)$ & Lower & $47(41.59)$ \\
\hline$¥ 6000-14,999$ & $57(50.44)$ & Normal & $65(57.52)$ \\
\hline$\geq ¥ 15,000$ & $21(18.58)$ & Higher & $1(0.88)$ \\
\hline Menopausal status & & PBF (\%) & \\
\hline Premenopausal & $39(34.51)$ & $<30$ & 32 (28.32) \\
\hline Postmenopausal & $74(65.49)$ & $\geq 30$ & $81(71.68)$ \\
\hline
\end{tabular}


three completed the body composition test in 3 months but refused to answer the questionnaire (Figure 1). The physical activity data of 96 participants were synchronized to the patients' health management system. The data of the other 22 participants could not be synchronized due to account authority.

\section{Baseline Characteristics of the Participants}

The average age of the participants was $48.83 \pm 8.44$ years, with the youngest being 27 years old and the oldest being 65 years old. The median time to surgery was 2.26 (1.553.64) years. Furthermore, $52.21 \%$ of the participants had college education and $92.4 \%$ were married. The proportion of patients with local and regional breast cancer was 61.06 and $38.94 \%$, respectively, with $72.57 \%$ luminal type, 9.73\% HER-2enriched, and $15.93 \%$ triple-negative. The participants with a normal BMI $\left(18.5-23.9 \mathrm{~kg} / \mathrm{m}^{2}\right)$ accounted for $65.49 \%$. The body composition at baseline showed that $41.59 \%$ of patients had SMM lower than normal [skeleton muscle index: SMM $(\mathrm{kg}) /$ height $(\mathrm{m})^{2}<7.8 \mathrm{~kg} / \mathrm{m}^{2}$ ] (23), and the PBF of $71.68 \%$ of patients was more than $30 \%$, which was an average PBF in women aged 45-49 years (24) (Table 1).

\section{Physical Activity Monitoring}

The median (quartile) wear days were 91 (89-91) days, with a minimum of 5 days due to lost equipment.

The number of daily walk steps of the participants was $8,851.28 \pm 2,399.31$, with median of $143.52 \mathrm{kcal}$ physical activity consumption. The daily walking time was $95.97 \pm 20.25 \mathrm{~min}$ on average, with $59.21 \%$ days reaching the set goal calorie consumption. The median running time was $5.11 \mathrm{~min}$, with

TABLE 2 | Physical activity status monitored using a wearable activity tracker.

\begin{tabular}{l} 
Characteristics \\
\hline Daily step counts, mean $\pm \mathrm{SD}$ \\
Daily PA calories (kcal), median (quartiles) \\
Daily walking time (minutes), mean $\pm \mathrm{SD}$ \\
Daily running time (minutes), median (quartiles) \\
Accumulated days \\
Reach standard days (\%)
\end{tabular}

Value

$8851.28 \pm 2399.31$

$143.52(116.06-170.13)$

$95.97 \pm 20.25$

$5.11(2.77-8.28)$

8314

$4923(59.21 \%)$ the first and the third quartiles being 2.77 and $8.28 \mathrm{~min}$, respectively (Table 2 ).

\section{Body Composition Change in 3 Months}

After a 3-month intervention, significant changes were observed in body weight, fat mass, BMI, PBF, BMR, and VFA; VFA had the most significant changes $\left(-6.54 \mathrm{~cm}^{2}\right)$. No significant changes were observed in protein mass and SMM (Table 3).

Body weight and BMI were reduced in patients who had chemotherapy, patients with or without endocrine therapy, patients with luminal $\mathrm{A}$ and luminal $\mathrm{B}$, triple-negative patients, patients who had undergone surgery, patients with or without lymph node positivity, patients with $\mathrm{BMI} \geq$ or $<24 \mathrm{~kg} / \mathrm{m}^{2}$, and patients of any age. Protein mass and SMM increased in patients without endocrine therapy, HER-2-enriched patients, lymph node-negative patients, patients with BMI $<24 \mathrm{~kg} / \mathrm{m}^{2}$, and patients aged more than 45 years. Fat mass, PBF, and VFA decreased in patients with chemotherapy, patients with or without endocrine therapy, patients with luminal A and luminal B, HER-2-enriched patients, patients who had undergone surgery, and patients with any BMI category and age (Table 4).

\section{Adverse Effects}

After the intervention, 99\% participants were satisfied with the program, and 110/113 were willing to continue wearing the device. Two had a dermatological allergy, three had a psychological burden (worried about not completing the calorie consumption goal), and one had uneasiness in sleeping as adverse effects.

\section{DISCUSSION}

This study showed that the body composition of breast cancer survivors improved through a wearable technology-based 3month intervention. Body weight, BMI, fat mass, PBF, BMR, and VFA also significantly decreased. The effect was consistent within most strata, indicating that patients could benefit from the intervention irrespective of disease characteristics and treatment. Loss of body fat mass was most significant in luminal $\mathrm{A}$ and luminal B subgroups in which patients were more sensitive to estrogen and aromatase released during adipocyte expansion.

TABLE 3 | Body composition change after 3-month wearable activity tracker intervention.

\begin{tabular}{|c|c|c|c|c|c|}
\hline Body composition & Baseline & In 3 months & Differences $(95 \% \mathrm{Cl})$ & $t$ & $P$ value \\
\hline Protein mass (kg) & $7.43 \pm 0.79$ & $7.46 \pm 0.78$ & 0.03 (-0.01 to 0.07$)$ & -1.322 & 0.189 \\
\hline SMM (kg) & $20.41 \pm 2.39$ & $20.52 \pm 2.35$ & 0.11 (-0.01 to 0.23$)$ & -1.893 & 0.061 \\
\hline BMI $\left(\mathrm{kg} / \mathrm{m}^{2}\right)$ & $22.77 \pm 2.80$ & $22.53 \pm 2.79$ & $-0.24(-0.34$ to -0.13$)$ & 4.576 & $<0.001^{*}$ \\
\hline PBF (\%) & $33.10 \pm 5.32$ & $32.00 \pm 5.46$ & $-1.10(-1.47$ to -0.73$)$ & 5.883 & $<0.001^{\star}$ \\
\hline VFA $\left(\mathrm{cm}^{2}\right)$ & $91.01 \pm 33.13$ & $84.15 \pm 32.09$ & $-6.86(-8.94$ to -4.78$)$ & 6.539 & $<0.001^{*}$ \\
\hline
\end{tabular}

*Statistically significant at $\alpha=0.05$. 
TABLE 4 | Body composition change in different subgroups.

\begin{tabular}{|c|c|c|c|c|c|c|c|c|c|}
\hline \multicolumn{2}{|c|}{ Characteristics } & \multicolumn{8}{|c|}{ Change mean $(95 \% \mathrm{Cl})$} \\
\hline & $N$ & Body weight & Protein mass & Fat mass & SMM & BMI & PBF & BMR & VFA \\
\hline \multicolumn{10}{|c|}{$\begin{array}{l}\text { Adjuvant } \\
\text { chemotherapy }\end{array}$} \\
\hline Yes & 101 & $-0.66^{\star}(-0.95$ to -0.37$)$ & $0.03(-0.01$ to 0.08$)$ & $-0.88^{*}(-1.16$ to -0.60$)$ & $0.12(-0.01$ to 0.25$)$ & $-0.26^{\star}(-0.37$ to -0.15$)$ & $-1.17^{\star}(-1.57$ to -0.78$)$ & $4.64^{*}(0.13-9.15)$ & $-7.11^{*}(-9.28$ to -4.94$)$ \\
\hline No & 12 & -0.27 (-1.03 to 0.48$)$ & $-0.02(-0.10$ to 0.06$)$ & $-0.29(-1.23$ to 0.64$)$ & $0.04(-0.19$ to 0.27$)$ & -0.10 (-0.40 to 0.20$)$ & $-0.56(-1.87$ to 0.75$)$ & $0.50(-11.04$ to 12.04$)$ & $-5.69(-14.14$ to 2.76$)$ \\
\hline \multicolumn{10}{|l|}{$\begin{array}{l}\text { Endocrine } \\
\text { therapy }\end{array}$} \\
\hline Yes & 82 & $-0.64^{\star}(-0.97,-0.30)$ & $0.01(-0.05$ to 0.06$)$ & $-0.75^{\star}(-1.06$ to -0.43$)$ & $0.06(-0.09$ to 0.20$)$ & $-0.24^{\star}(-0.37$ to -0.11$)$ & $-0.97^{\star}(-1.41$ to -0.52$)$ & $2.33(-2.77$ to 7.43$)$ & $-6.49^{*}(-9.02$ to -3.96$)$ \\
\hline No & 31 & $-0.58^{\star}(-1.01$ to -0.15$)$ & $0.08^{*}(0.01-0.16)$ & $-1.00^{*}(-1.50$ to -0.49$)$ & $0.24^{*}(0.04-0.43)$ & $-0.24^{*}(-0.41$ to -0.07$)$ & $-1.47^{*}(-2.20$ to -0.74$)$ & $9.06^{*}(1.92-16.21)$ & $-8.18^{*}(-12.01$ to -4.35$)$ \\
\hline \multicolumn{10}{|l|}{ Molecular } \\
\hline $\begin{array}{l}\text { Luminal A } \\
\text { and luminal } \\
\text { B }\end{array}$ & 82 & $-0.65^{\star}(-0.99$ to -0.31$)$ & $0.02(-0.04$ to 0.07$)$ & $-0.81^{*}(-1.13$ to -0.48$)$ & $0.09(-0.06$ to 0.23$)$ & $-0.25^{\star}(-0.38$ to -0.12$)$ & $-1.08^{\star}(-1.54$ to -0.61$)$ & $3.36(-1.80$ to 8.52$)$ & $-6.78^{\star}(-9.34$ to -4.21$)$ \\
\hline $\begin{array}{l}\text { HER-2 } \\
\text { enriched }\end{array}$ & 11 & $-0.37(-1.08$ to 0.33$)$ & $0.17^{\star}(0.04-0.30)$ & $-1.15^{\star}(-1.71$ to -0.58$)$ & $0.44^{\star}(0.08-0.79)$ & $-0.16(-0.43$ to 0.10$)$ & $-1.85^{\star}(-2.71$ to -0.98$)$ & $16.73^{\star}(3.41-30.05)$ & $-11.03^{*}(-16.24$ to -5.81$)$ \\
\hline $\begin{array}{l}\text { Triple } \\
\text { negative }\end{array}$ & 18 & $-0.67^{\star}(-1.24$ to -0.11$)$ & $-0.02(-0.10$ to 0.06$)$ & $-0.64(-1.33$ to 0.05$)$ & $-0.02(-0.26$ to 0.22$)$ & $-0.27^{\star}(-0.50$ to -0.04$)$ & $-0.73(-1.67$ to 0.21$)$ & $-0.72(-9.03$ to 7.59$)$ & $-5.78^{\star}(-11.29$ to -0.28$)$ \\
\hline $\begin{array}{c}\text { Not } \\
\text { identified }\end{array}$ & 2 & $-0.25(-13.59$ to 13.09$)$ & $0.10(-1.17$ to 1.37$)$ & $-0.90(-21.23$ to 19.43$)$ & $0.40(-4.68$ to 5.48$)$ & $-0.10(-5.18$ to 4.98$)$ & $-1.70(-29.65$ to 26.25$)$ & 13.50 (-132.62 to 159.62$)$ & $-2.55(-95.94$ to 90.84$)$ \\
\hline \multicolumn{10}{|l|}{$\begin{array}{l}\text { Time to } \\
\text { surgery }\end{array}$} \\
\hline $1 \sim$ & 44 & $-0.64^{\star}(-1.01$ to -0.26$)$ & 0.05 (-0.01 to 0.12$)$ & $-0.97^{\star}(-1.39$ to -0.56$)$ & $0.21^{\star}(0.04-0.37)$ & $-0.25^{\star}(-0.40$ to -0.10$)$ & $-1.39^{\star}(-1.98$ to -0.79$)$ & $7.31^{*}(1.48-13.14)$ & $-8.87^{\star}(-12.42$ to -5.32$)$ \\
\hline $2 \sim$ & 101 & $-0.67^{\star}(-1.17$ to -0.17$)$ & $0.01(-0.08$ to 0.11$)$ & $-0.72^{\star}(-1.34$ to -0.10$)$ & $0.00(-0.29$ to 0.29$)$ & $-0.26^{\star}(-0.46$ to -0.06$)$ & $-0.93^{\star}(-1.80$ to -0.06$)$ & $1.13(-8.41$ to 10.68$)$ & $-5.34^{*}(-10.39$ to -0.29$)$ \\
\hline $3+$ & 12 & $-0.57^{\star}(-1.11$ to -0.03$)$ & $0.00(-0.07$ to 0.08$)$ & $-0.69^{*}(-1.12$ to -0.25$)$ & $0.06(-0.16-0.27)$ & $-0.22^{\star}(-0.43$ to -0.01$)$ & $-0.88^{*}(-1.50$ to -0.26$)$ & $2.27(-5.53$ to 10.07$)$ & $-5.62^{*}(-8.56$ to -2.69$)$ \\
\hline \multicolumn{10}{|l|}{$\begin{array}{l}\text { Lymph } \\
\text { node }\end{array}$} \\
\hline Negative & 69 & $-0.42^{\star}(-0.71$ to -0.12$)$ & $0.05^{\star}(0.00-0.10)$ & $-0.68^{\star}(-1.01$ to -0.35$)$ & $0.15^{\star}(0.02-0.29)$ & $-0.16^{*}(-0.28$ to -0.04$)$ & $-1.00^{\star}(-1.48$ to -0.53$)$ & $5.57^{\star}(0.60-10.53)$ & $-6.28^{*}(-8.90$ to -3.65$)$ \\
\hline Positive & 44 & $-0.95^{\star}(-1.46$ to -0.44$)$ & $-0.01(-0.09$ to 0.07$)$ & $-1.03^{\star}(-1.49$ to -0.58$)$ & $0.04(-0.18$ to 0.26$)$ & $-0.37^{\star}(-0.57$ to -0.18$)$ & $-1.28^{\star}(-1.92$ to -0.64$)$ & 2.00 (-5.58 to 9.58$)$ & $-8.05^{\star}(-11.60$ to -4.50$)$ \\
\hline \multicolumn{10}{|l|}{$\begin{array}{l}\text { Baseline } \\
\text { BMI } \\
\left(\mathrm{kg} / \mathrm{m}^{2}\right)\end{array}$} \\
\hline$\geq 24$ & 35 & $-0.98^{\star}(-1.64$ to -0.33$)$ & $-0.03(-0.12$ to 0.06$)$ & $-0.90^{*}(-1.42,-0.37)$ & $-0.09(-0.33$ to 0.15$)$ & $-0.38^{*}(-0.63$ to -0.14$)$ & $-0.87^{\star}(-1.43$ to -0.32$)$ & $-1.91(-10.34$ to 6.53$)$ & $-7.22^{*}(-11.26$ to -3.18$)$ \\
\hline$<4$ & 83 & $-0.45^{\star}(-0.71$ to -0.19$)$ & $0.05^{\star}(0.01-0.10)$ & $-0.77^{\star}(-1.08,-0.47)$ & $0.19^{*}(0.06-0.32)$ & $-0.18^{*}(-0.28$ to -0.07$)$ & $-1.19^{\star}(-1.67$ to -0.72$)$ & $6.91^{*}(2.27-11.56)$ & $-6.71^{*}(-9.19$ to -4.24$)$ \\
\hline \multicolumn{10}{|l|}{ Age group } \\
\hline$\leq 45$ & 42 & $-0.76^{\star}(-1.31$ to -0.22$)$ & $-0.03(-0.11$ to 0.06$)$ & $-0.70^{\star}(-1.17,-0.22)$ & $-0.07(-0.29$ to 0.16$)$ & $-0.29^{*}(-0.50$ to -0.08$)$ & $-0.85^{*}(-1.54$ to -0.16$)$ & $-1.31(-9.15$ to 6.53$)$ & $-4.67^{\star}(-7.98$ to -1.37$)$ \\
\hline$>45$ & 71 & $-0.53^{\star}(-0.82$ to -0.25$)$ & $0.06^{\star}(0.01-0.11)$ & $-0.89^{*}(-1.21$ to -0.57$)$ & $0.22^{*}(0.09-0.35)$ & $-0.21^{*}(-0.33$ to -0.10$)$ & $-1.26^{*}(-1.71$ to -0.82$)$ & $7.50^{*}(2.79-12.21)$ & $-8.33^{*}(-11.03$ to -5.63$)$ \\
\hline
\end{tabular}

${ }^{*}$ Statistically significant at $\alpha=0.05$. 
Although $65.49 \%$ of survivors showed a normal BMI at baseline assessment in this randomly selected sample, $71.68 \%$ of survivors had a PBF more than $30 \%$, and $41.59 \%$ had low SMM, indicating a poor body composition among breast cancer survivors. Obesity is related to poorer outcomes with increased mortality among survivors $(6,25,26)$, and most patients with breast cancer would have a weight gain after diagnosis (27).

A recent study showed that wearable technology-based intervention effectively increased the MVPA and reduced the sedation time (28). Studies also showed that wearable devices increased self-awareness and motivation for physical activities. Doctor monitoring and peer support were also important in the use of wearable activity trackers (29). Although the daily step counting was more than 8,800 , the running time was very low among the participants, with a median time of only $5.11 \mathrm{~min}$ daily. The physical activity pattern varied from person to person. Studies suggested that patients planning to lose weight could better benefit from a continuous aerobic exercise in which the heart rate reached the target heart rate or caused energy deficit, as in the LISA (30) and ENERGY (31) study. However, the present study showed that, even if the exercise intensity was far from vigorous with enough time of moderate exercise, breast cancer survivors could still obtain benefits from the improvement in body weight and body composition. However, the improvement was mainly in terms of a decrease in body fat, while protein mass and SMM showed no significant improvement. This could be due to intervention monitoring and setting the goal for calorie consumption, with no track of anti-resistance training, which improved the SMM. It was also a safer way, compared with high-intensity exercise, for breast cancer survivors whose average age was around 50 years since a large number of hormone receptor-positive patients received aromatase inhibitor drugs for a long time, causing osteoporosis (32). A recent study also showed that older women with an average of 7,500 steps/day had reduced all-cause mortality, and the benefit was not associated with intensity (33).

Since breast cancer has a high incidence rate and a relatively good prognosis, the number of breast cancer survivors is huge. The 5-year prevalence of breast cancer is nearly 1.1 million in China alone (34). As an appropriate technology to be generalized, the wearable technology was considered to be one of the choices with preferable features of safety, acceptability, and cost-effectiveness. Besides causing an improvement in body composition, this low-cost comprehensive care, including body composition analysis, health education, and wearable device application, is welcomed by participants with nearly no harm, strong interaction, and fun. This study used a wearable activity tracker to monitor the activity, which could reflect the objective and the real status of each participant. Besides BMI, body composition might be an additional indicator to monitor the achievement of lifestyle intervention. In addition to breast cancer, colorectal cancer, esophageal adenocarcinoma, and endometrial cancer share a common risk factor of body fat. The wearable technology also has the potential to be applied in the long-term survival management of patients with postoperative early stage cancer. Its benefits need further investigation.

However, the present study also had some limitations. First, the baseline physical activity assessment before the wearable equipment was delivered was hard to collect, making it difficult to compare the physical activity volume and contributing to the effects of the increase in physical activity volume. Attempts were made to evaluate the activity status before the intervention, but the data were far from consistent with what the wearable equipment collected. Second, the study was not designed as a randomized controlled trial because the technology was easy to be accessed by those not even enrolled in the study and the patients in the center had frequent interaction and communication, which might have led to contamination of the randomized controlled trial. Hence, it was hard to identify which part of the interventions contributed to the benefit during the whole intervention period. Third, the result of this study could not be generalized to all patients with breast cancer because patients in the advanced stage were not included. The management of advanced-stage patients would be totally different due to different treatment regimens and physical conditions, especially patients with cachexia. Fourth, the participants were all patients capable of using wearable devices, which compromised the representativeness of the patients. When upscaling the intervention, such factors should be taken into consideration, and an improvement in usability needs to be further optimized.

Future studies should involve more indicators, especially biomarkers such as leptins, C-reactive protein, and TNF- $\alpha$, and should have expanded sample size and better study design to better reflect the effect of wearable technology intervention on breast cancer survivors.

\section{CONCLUSION}

The wearable technology-based comprehensive intervention can help breast cancer survivors in controlling body weight and improving body composition, especially in reducing body fat, thus improving the prognosis. The effect was consistent within most strata in this study, indicating that patients with different age, staging, and molecular profile and with or without chemotherapy or endocrine therapy could benefit from the intervention.

\section{DATA AVAILABILITY STATEMENT}

The raw data supporting the conclusions of this article will be made available by the authors, without undue reservation.

\section{ETHICS STATEMENT}

The studies involving human participants were reviewed and approved by Fudan University Shanghai Cancer Center Research Committee. The patients/participants provided their written informed consent to participate in this study. 


\section{AUTHOR CONTRIBUTIONS}

$\mathrm{CZ}$ and $\mathrm{YZ}$ conceived and designed the project and wrote the manuscript. ZS and YZ supervised the study. JC, LT, and JQ recruited the participants. MM, CZ, ZW, and JS collected the data. YL and HD provided body composition test and nutritional consulting for the participants. QJ provided a patient's management platform. HW provided the data interface transferring wearable equipment data to the database. All the authors contributed to the study conception and design, read, reviewed, and approved the final manuscript.

\section{REFERENCES}

1. Bray F, Ferlay J, Soerjomataram I, Siegel RL, Torre LA, Jemal A. Global cancer statistics 2018: GLOBOCAN estimates of incidence and mortality worldwide for 36 cancers in 185 countries. CA Cancer J Clin. (2018) 68:394-424. doi: $10.3322 /$ caac. 21492

2. Allemani C, Matsuda T, Di Carlo V, Harewood R, Matz M, Nikšić M, et al. Global surveillance of trends in cancer survival 2000-14 (CONCORD-3): analysis of individual records for 37513025 patients diagnosed with one of 18 cancers from 322 population-based registries in 71 countries. Lancet. (2018) 391:1023-75.

3. Shanghai Municipal Center for Disease Prevention and Control 2015 Shanghai Cancer Report. Shanghai: Shanghai Municipal Center for Disease Prevention and Control (2015).

4. van den Berg MMGA, Winkels RM, de Kruif JTCM, van Laarhoven HWM, Visser M, de Vries JHM, et al. Weight change during chemotherapy in breast cancer patients: a meta-analysis. BMC Cancer. (2017) 17:259. doi: 10.1186/ s12885-017-3242-4

5. Faber-Langendoen K. Weight gain in women receiving adjuvant chemotherapy for breast cancer. JAMA. (1996) 276:855-6. doi: 10.1001/jama.1996.03540110009004

6. Neuhouser ML, Aragaki AK, Prentice RL, Manson JE, Chlebowski R, Carty $\mathrm{CL}$, et al. Overweight, obesity, and postmenopausal invasive breast cancer risk. JAMA Oncol. (2015) 1:611. doi: 10.1001/jamaoncol.2015.1546

7. Kwan ML, Chen WY, Weltzien E, Beasley JM, Lu W, Nechuta SJ, et al. P1-08-02: pre-diagnosis body mass index and breast cancer prognosis and survival: report from the after breast cancer pooling project. Cancer Res. (2011) 71:P1-08-02. doi: 10.1158/0008-5472.SABCS11-P1-08-02

8. Chan DSM, Vieira AR, Aune D, Bandera EV, Greenwood DC, McTiernan A, et al. Body mass index and survival in women with breast cancer-systematic literature review and meta-analysis of 82 follow-up studies. Ann Oncol. (2014) 25:1901-14. doi: 10.1093/annonc/mdu042

9. World Cancer Research Fund International American Institute For Cancer Research. Diet, Nutrition, Physical Activity and Breast Cancer Survivors. London: World Cancer Research Fund International (2018).

10. Gilbert CA, Slingerland JM. Cytokines, obesity, and cancer: new insights on mechanisms linking obesity to cancer risk and progression. Annu Rev Med. (2013) 64:45-57. doi: 10.1146/annurev-med-121211-091527

11. Picon-Ruiz M, Morata-Tarifa C, Valle-Goffin JJ, Friedman ER, Slingerland JM. Obesity and adverse breast cancer risk and outcome: mechanistic insights and strategies for intervention. CA Cancer J Clin. (2017) 67:378-97. doi: 10.3322/caac. 21405

12. Friedenreich CM, Neilson HK, Farris MS, Courneya KS. Physical activity and cancer outcomes: a precision medicine approach. Clin Cancer Res. (2016) 22:4766-75. doi: 10.1158/1078-0432.CCR-16-0067

13. Lahart IM, Metsios GS, Nevill AM, Carmichael AR. Physical activity, risk of death and recurrence in breast cancer survivors: a systematic review and meta-analysis of epidemiological studies. Acta Oncol. (2015) 54:635-54. doi: 10.3109/0284186X.2014.998275

14. Schmid D, Leitzmann MF. Association between physical activity and mortality among breast cancer and colorectal cancer survivors: a systematic review and meta-analysis. Ann Oncol. (2014) 25:1293-311. doi: 10.1093/annonc/mdu012

15. Beasley JM, Kwan ML, Chen WY, Weltzien EK, Kroenke CH, Lu W, et al. Meeting the physical activity guidelines and survival after breast cancer:

\section{FUNDING}

This study was supported by the Fudan University Shanghai Cancer Center Institutional Fund (Grant Numbers YJRC1701 and GL201702).

\section{ACKNOWLEDGMENTS}

We thank Yankang Club for organizing patients' recruitment and Ms. Zhihong Zhang and Jing Yuan for their help in data collection.

findings from the after breast cancer pooling project. Breast Cancer Res Treat. (2012) 131:637-43. doi: 10.1007/s10549-011-1770-1

16. Chlebowski RT, Reeves MM. Weight loss randomized intervention trials in female cancer survivors. J Clin Oncol. (2016) 34:4238-48. doi: 10.1200/JCO. 2016.69.4026

17. Phillips SM, Cadmus-Bertram L, Rosenberg D, Buman MP, Lynch BM. Wearable technology and physical activity in chronic disease: opportunities and challenges. Am J Prev Med. (2018) 54:144-50. doi: 10.1016/j.amepre.2017. 08.015

18. Rehman H, Kamal AK, Sayani S, Morris PB, Merchant AT, Virani SS. Using mobile health (mHealth) technology in the management of diabetes mellitus, physical inactivity, and smoking. Curr Atheroscler Rep. (2017) 19:16. doi: 10.1007/s11883-017-0650-5

19. Breast Group, Women's Health Branch, Chinese Preventive Medical Association Guidelines on life-style modification for Chinese breast cancer survivors. Chin J Surg. (2017) 55:81-5.

20. Cella DF, Tulsky DS, Gray G, Sarafian B, Linn E, Bonomi A, et al. The functional assessment of cancer therapy scale: development and validation of the general measure. J Clin Oncol. (1993) 11:570-9. doi: 10.1200/JCO.1993.11. 3.570

21. Wan C, Zhang D, Yang Z, Tu X, Tang W, Feng C, et al. Validation of the simplified Chinese version of the FACT-B for measuring quality of life for patients with breast cancer. Breast Cancer Res TR. (2007) 106:413-8. doi: 10.1007/s10549-007-9511-1

22. Sergi G, De Rui M, Stubbs B, Veronese N, Manzato E. Measurement of lean body mass using bioelectrical impedance analysis: a consideration of the pros and cons. Aging Clin Exp Res. (2017) 29:591-7. doi: 10.1007/s40520-0160622-6

23. Chen L, Liu L, Woo J, Assantachai P, Auyeung T, Bahyah KS, et al. Sarcopenia in Asia: consensus report of the Asian working group for sarcopenia. J Am Med Dir Assoc. (2014) 15:95-101. doi: 10.1016/j.jamda.2013. 11.025

24. Ho-Pham LT, Campbell LV, Nguyen TV. More on body fat cutoff points. Mayo Clin Proc. (2011) 86:584-5. doi: 10.4065/mcp.2011.0097

25. Jiralerspong S, Goodwin PJ. Obesity and breast cancer prognosis: evidence, challenges, and opportunities. J Clin Oncol. (2016) 34:4203-16. doi: 10.1200/ JCO.2016.68.4480

26. Chen X, Lu W, Zheng W, Gu K, Chen Z, Zheng Y, et al. Obesity and weight change in relation to breast cancer survival. Breast Cancer Res Treat. (2010) 122:823-33. doi: 10.1007/s10549-009-0708-3

27. Chen X, Lu W, Gu K, Chen Z, Zheng Y, Zheng W, et al. Weight change and its correlates among breast cancer survivors. Nutr Cancer. (2011) 63:538-48. doi: 10.1080/01635581.2011.539316

28. Lynch BM, Nguyen NH, Moore MM, Reeves MM, Rosenberg DE, Boyle $\mathrm{T}$, et al. A randomized controlled trial of a wearable technology-based intervention for increasing moderate to vigorous physical activity and reducing sedentary behavior in breast cancer survivors: the ACTIVATE Trial. Cancer Am Cancer Soc. (2019) 125:2846-55. doi: 10.1002/cncr. 32143

29. Nguyen NH, Hadgraft NT, Moore MM, Rosenberg DE, Lynch C, Reeves MM, et al. A qualitative evaluation of breast cancer survivors' acceptance of and preferences for consumer wearable technology activity trackers. Support Care Cancer. (2017) 25:3375-84. doi: 10.1007/s00520-0173756-y 
30. Goodwin PJ, Segal RJ, Vallis M, Ligibel JA, Pond GR, Robidoux A, et al. Randomized trial of a telephone-based weight loss intervention in postmenopausal women with breast cancer receiving letrozole: the LISA trial. J Clin Oncol. (2014) 32:2231-9. doi: 10.1200/JCO.2013.53. 1517

31. Demark-Wahnefried W, Colditz GA, Rock CL, Sedjo RL, Liu J, Wolin KY, et al. Quality of life outcomes from the exercise and nutrition enhance recovery and good health for you (ENERGY)-randomized weight loss trial among breast cancer survivors. Breast Cancer Res TR. (2015) 154:329-37. doi: 10.1007/ s10549-015-3627-5

32. Goss PE, Ingle JN, Pritchard KI, Robert NJ, Muss H, Gralow J, et al. Extending aromatase-inhibitor adjuvant therapy to 10 years. New Engl J Med. (2016) 375:209-19. doi: 10.1056/NEJMoa1604700

33. Lee I, Shiroma EJ, Kamada M, Bassett DR, Matthews CE, Buring JE. Association of step volume and intensity with all-cause mortality in older women. JAMA Intern Med. (2019) 179:1105-12. doi: 10.1001/jamainternmed. 2019.0899
34. IARC Cancer Today. 2018. (2018). Available online at: https://gco.iarc.fr/ today/ (accessed May 18, 2020).

Conflict of Interest: HW was employed by Huami Information Technology Co., Ltd. and QJ was employed by Shanghai Ruochu Information Technology Co., Ltd.

The remaining authors declare that the research was conducted in the absence of any commercial or financial relationships that could be construed as a potential conflict of interest.

Copyright (c) 2020 Zhou, Mo, Wang, Shen, Chen, Tang, Qiu, Ling, Ding, Jiang, Wang, Shao and Zheng. This is an open-access article distributed under the terms of the Creative Commons Attribution License (CC BY). The use, distribution or reproduction in other forums is permitted, provided the original author(s) and the copyright owner(s) are credited and that the original publication in this journal is cited, in accordance with accepted academic practice. No use, distribution or reproduction is permitted which does not comply with these terms. 